\title{
Human immunoglobulin treatment of multifocal motor neuropathy and polyneuropathy associated with monoclonal gammopathy
}

\author{
J M Leger, A Ben Younes-Chennoufi, B Chassande, G Davila, P Bouche, N Baumann, \\ P Brunet
}

\begin{abstract}
Intravenous human immune globulin (IVIg) has been proposed for the treatment of various peripheral neuropathies that are considered to be immunemediated. The results are reported of an open trial conducted in multifocal motor neuropathy and polyneuropathy associated with monoclonal gammopathy. Six cases with multifocal motor neuropathy, selected on clinical and electrophysiological criteria (four of six patients also had significantly high anti-GM1 titres), received IVIg monthly, at doses varying from 1.6 to $2.5 \mathrm{mg} / \mathrm{kg}$, over three to 13 months. The initial response to treatment was dramatic in $3 / 6$ cases (with improvement of at least two grades on the MRC scale in the five more severely affected muscles). The final evaluation showed a good result in 4/6 cases, but the conduction blocks were not significantly reduced. In 13 other cases with polyneuropathy associated with IgM monoclonal gammopathy of unknown significance, IVIg was of benefit, with improvement of at least one grade on the Prineas score, in $4 / 7$ cases previously treated with immunosuppression and $2 / 3$ cases not treated before IVIg. In the last group of four patients with polyneuropathy and IgG monoclonal gammopathy, IVIg was followed by clinical improvement in the two cases with a chronic demyelinating polyneuropathy.
\end{abstract}

Intravenous human immune globulin (IVIg) has been proposed for the treatment of various peripheral neuropathies that are considered to be immune-mediated: GuillainBarré syndrome, ${ }^{1}$ chronic inflammatory demyelinating polyneuropathy (CIDP), ${ }^{2-4}$ multifocal motor neuropathy, ${ }^{5}$ polyneuropathy associated with IgM monoclonal gammopathy. ${ }^{6}$ In this paper, we focus on IVIg treatments in multifocal motor neuropathy and in polyneuropathy associated with monoclonal gammopathy. We review previous reports and give our own results on some studies that have been conducted over the past two years.

Multifocal motor neuropathy

The syndrome of multifocal motor neuro- pathy (MMN) with persistent conduction blocks was described by Parry and Clarke ${ }^{7}$ and by Roth et al. ${ }^{8}$ Lewis et al ${ }^{9}$ previously reported a similar syndrome of multifocal sensorimotor neuropathy. These syndromes have been characterised according to clinical, electrophysiological and immunological criteria. They have been discussed as variants of either chronic inflammatory demyelinating polyneuropathy (CIDP) or motor neuron disease. $^{7}$

Clinically, MMN is characterised by progressive weakness with multifocal distribution. Muscular atrophy, cramps, myokymia, fasciculations, preserved reflexes, paucity or complete lack of sensory abnormalities are common features which are similar to those occurring in motor neuron diseases. When more nerves are affected in the course of the disease, these symptoms and signs may become more widespread and mimick those observed in amyotrophic lateral sclerosis. Nevertheless, the following distinctive characteristics define $\mathrm{MMN}$ : there is no bulbar involvement and no upper motor neuron signs; motor involvement usually starts in the upper limbs asymetrically, and remain prominent in the arms; careful examination discloses motor involvement and atrophy in individual peripheral nerve territories, so that affected nerves may coexist with normal nerves in the same limb. Tendon reflexes are diminished and frequently absent in the upper limbs. Finally, the course of MMN is usually slowly progressive over years, or even decades, and most of the patients remain ambulatory with various motor handicaps.

Electrodiagnostic studies usually distinguish $M M N$ from MND. Motor nerve conduction studies disclose focal or multifocal conduction blocks confined to motor axons. They may occur at any level, but are commonest in the forearms. The reduction of the amplitude of the evoked motor potential, obtained after proximal stimulation of the motor nerve, is frequently severe $(>80 \%)$, and usually accompanied by severe conduction slowing and dispersion of the evoked motor response. These abnormalities of conduction are restricted to short segments of nerve ranging from $3-10 \mathrm{cms}$ in length. ${ }^{8}$ Needle electromyography may show fibrillations, fasciculations and myokymia in the affected muscles.

Antibodies directed to GM1 ganglioside in 
Table 1 Clinical and laboratory features of patients with $M M N$

\begin{tabular}{|c|c|c|c|c|c|c|c|c|}
\hline \multirow[b]{2}{*}{$\begin{array}{l}\text { Number } \\
\text { of cases }\end{array}$} & \multirow[b]{2}{*}{ Sex/age } & \multirow[b]{2}{*}{$\begin{array}{l}\text { Course } \\
\text { (years) }\end{array}$} & \multirow[b]{2}{*}{$\begin{array}{l}\text { Distribution in } \\
\text { motor nerves }\end{array}$} & \multirow[b]{2}{*}{$\begin{array}{l}\text { Total number } \\
\text { of infusions }\end{array}$} & \multicolumn{3}{|c|}{ Clinical evolution } & \multirow[b]{2}{*}{$\begin{array}{l}\text { Anti-GM1 antibody } \\
\text { titres before IVIg }\end{array}$} \\
\hline & & & & & $\begin{array}{l}\text { First } \\
\text { response }\end{array}$ & $N^{*}$ & $\begin{array}{l}\text { Final } \\
\text { result }\end{array}$ & \\
\hline 1 & $\begin{array}{l}M \\
34\end{array}$ & 8 & $\begin{array}{l}\text { R median } \\
\text { L ulnar + radial } \\
\text { L peroneal }\end{array}$ & 13 & dramatic & 10 & $\begin{array}{l}\text { Persistent } \\
\text { improvement }\end{array}$ & 0 \\
\hline 2 & $\begin{array}{l}\mathbf{M} \\
50\end{array}$ & 15 & $\begin{array}{l}\mathbf{R} \text { median } \\
2 \text { ulnar }+ \text { radial } \\
\mathbf{R} \text { peroneal }\end{array}$ & 8 & slight & 5 & Deterioration & $1 / 1600$ \\
\hline 3 & $\begin{array}{l}M \\
46\end{array}$ & 15 & $\begin{array}{l}\mathbf{R} \text { median } \\
\mathbf{L} \text { ulnar } \\
\mathbf{R} \text { peroneal }\end{array}$ & 8 & dramatic & 6 & $\begin{array}{l}\text { Slight } \\
\text { persistent } \\
\text { improvement }\end{array}$ & $1 / 400$ \\
\hline 4 & $\begin{array}{l}M \\
29\end{array}$ & 22 & $\begin{array}{l}2 \text { ulnar } \\
\text { L median } \\
\text { L peroneal }\end{array}$ & 6 & dramatic & 6 & $\begin{array}{l}\text { Persistent } \\
\text { improvement }\end{array}$ & $1 / 12800$ \\
\hline 5 & $\begin{array}{l}M \\
46\end{array}$ & 3 & $\begin{array}{l}\mathrm{R} \text { median }+ \text { ulnar } \\
\mathrm{L} \text { peroneal }\end{array}$ & 8 & mild & 5 & $\begin{array}{l}\text { Mild } \\
\text { persistent if } \\
\text { repeated }\end{array}$ & $1 / 3200$ \\
\hline 6 & $\begin{array}{l}M \\
35\end{array}$ & 4 & $\begin{array}{l}\mathrm{R} \text { radial } \\
\text { median }\end{array}$ & 3 & 0 & & & $1 / 3200$ \\
\hline
\end{tabular}

$\mathrm{N}^{\star}:$ Number of infusions corresponding to improvement.

MMN were first reported in 1988 in two cases. ${ }^{10}$ Subsequently, the same authors found high titres of these antibodies (80-90\%) in a large series of $M M N$. It was then suggested that antibodies to GM1 ganglioside may play a role in the pathogenesis of $M M N$. Other studies, however, did not confirm these results: in a French multicentre series of 25 cases, ${ }^{11}$ significantly high titres were found in only $41 \%$ of cases. Similar results were reported by Lange et al. ${ }^{12}$ Conversely, the same antiglycolipid antibodies are found in motor neuron diseases such as ALS, GBS, CIDP and several autoimmune diseases without neurological involvement.

There are relatively few papers on the treatment of MMN. Most of them used prednisone in doses ranging from $25-100 \mathrm{mg} /$ day, with rare improvement ${ }^{713}$ and sometimes deterioration. ${ }^{14}$ Plasma exchange appears to be of no benefit. High dose intravenous cyclophosphamide has been tried in small studies, and in an open study on 25 cases $^{15}$ a beneficial effect was shown in eight cases, accompanied by a reduction in anti-GM1 antibody titres; but conduction blocks did not resolve. IVIg has been tried in numerous studies. ${ }^{16-18}$ In the series of nine patients reported by Chaudhry et $a l,{ }^{5}$ strength (measured in the five more affected muscles) improved in all cases three to 10 days after treatment, with improvement peaking at two weeks and lasting for an average of two months; the range of functional improvement varied from dramatic to mild. These authors found a reduction of the degree of motor conduction blocks in $7 / 8$ patients. The serum anti-GM1 antibody titres did not change. Four of the five patients treated by Nobile-Orazio et $a l^{17}$ had both increased levels of anti-asialo-GM1 and a good response to IVIg with complete recovery in one case and persistent improvement in three others. This was maintained by periodic two day infusions during six to 12 months. These authors observed a reduction of conduction blocks in most, but not all, motor nerves, and no significant changes in antibody titres. Among the 12 patients with motor neuron syndrome treated with IVIg versus placebo in a double-blind, placebo-controlled study, Azulay et al ${ }^{18}$ found that only the five cases with conduction blocks responded to IVIg treatment.

We treated (preliminary reports in three cases $^{19}$ ) six patients with multifocal motor neuropathy and conduction blocks. Clinical and electrophysiological data are summarised in table 1 . There were six men aged 34 to 50 . The course of the peripheral neuropathy ranged from three to 22 years, but the diagnosis was established on electrophysiological criteria during the last four years. Except for case 6 , who had a focal motor involvement of the right radial nerve, all patients had a motor multifocal neuropathy with at least two partial conduction blocks defined with the following criteria: $>50 \%$ reduction in both the compound muscle action potentials (CMAP) amplitude and the negative peak area on proximal stimulation compared with the distally stimulated response, with a $<15 \%$ change in the negative peak duration. Anti-GM1 ganglioside antibody titres were measured by enzyme-linked immunosorbent assay (ELISA) and immunodetection on thin-layer chromatography (TLC) according to methods previously reported ${ }^{20}: 4 / 6$ patients (cases $2,4,5$ and 6) had significantly high titres. All patients received IVIg (Bio-Transfusion) at doses varying from 1.6 to $2.4 \mathrm{mg} / \mathrm{kg}$ over a period of two to five days, every month during three to 13 months. For the follow up, the same examiner measured the strength of each patient at baseline and before/after each series of infusions, using both the MRC scale and a functional evaluation (adapted from the Rankin score used for CIDP).

The results are summarised in table 1 . The initial response to treatment was considered to be dramatic in 3/6 patients (cases 1, 3 and 4) with improvement of at least two grades on the MRC scale in the five more affected muscles; it was mild in case 5 and slight in case 2; case 6 who had a focal neuropathy did not respond to treatment and infusions were stopped. In the five responders, we observed a diminution of the response to treatment: a plateau was reached after five to six monthly IVIg infusions in cases 2, 3, 4 and 5, and after 10 months in case 1 (see column $N^{\star}$ in table 1 , 
indicating the number of beneficial series of infusions). The final evaluation (made between six and 13 months, see column table 1) indicated that motor improvement remained unchanged in four cases despite repeated IVIg infusions (excellent in cases 1 and 4 , mild in case 5 and slight in case 3 ). In case 2 , we observed a subsequent motor deterioration. Electrophysiological study failed to find a significant reduction of the degree of conduction block in all cases studied. This point has been a source of discussion in previous papers. Chaudhry et $a^{5}$ and NobileOrazio et $a l^{17}$ found a significant reduction of conduction block, but as was found with our cases other authors did not. ${ }^{18}$ This lack of correlation may be due to persistent differential dispersion and phase cancellation in affected nerves. In addition, some blocks may be located in very proximal segments of motor nerves and could not be measured by conventional electrodiagnostic studies.

\section{Polyneuropathy associated with IgM monoclonal gammopathy}

Polyneuropathy associated with Waldenström's disease was first recognised 30 years ago. ${ }^{21}$ The concept of "monoclonal gammopathy of unknown significance" (MGUS) is more recent. Smith et al ${ }^{22}$ reported the first large series of polyneuropathies associated with an IgM-MGUS. The main point was that these polyneuropathies seem to constitute a well-characterised group with clinical, electrophysiological and pathological features indicating a demyelinating process. ${ }^{23}$ In addition Latov et al ${ }^{24}$ showed that the pathological IgM binds to MAG (myelin-associated glycoprotein), a protein which is present in human peripheral nerve myelin. From this date, numerous other IgM antibody activities directed to other myelin nerve antigens have been widely described. ${ }^{25} 26$ Anti-MAG antibody activity and antiglycolipid antibody activity (mainly directed to sulphoglucuronyl glycolipids (SGGL)) which correspond to the same oligosaccharide epitope as MAG) seem to be highly correlated with the demyelinating process. In our series of 40 cases, ${ }^{27}$ in 33 cases there was an excellent correlation between electrophysiological features of demyelinating polyneuropathy, and either anti-MAG activity ( 26 cases, $\mathrm{p}<0.0001$ ), or anti-SGGL activity (26 cases, $p<0.01$ ). The course is usually slowly progressive and some cases remain stable for years, but in most, sensory disturbances worsen and a distal motor involvement may occur, leading to a disability that is probably underestimated. In our series, ${ }^{27}$ a third of patients were unable to walk without support and became ADL dependent.

Many open trials with immunosuppressive drugs (chlorambucil: 28; cyclophosphamide: 29 ) or plasma exchange $(P E)^{30}$ have been widely conducted. We reported the results of a randomised control study ${ }^{31}$ conducted on 44 patients with deteriorating polyneuropathy and IgM monoclonal gammopathy (mainly MGUS). Patients were treated with either chlorambucil alone for one year, or chlorambucil in combination with $15 \mathrm{PE}$ sessions within the first four months. We found that one year of treatment with chlorambucil was followed by clinical improvement of the peripheral neuropathy in only one third of patients. Plasma exchange did not seem to bring any additional effect when comparing the two groups.

The use of IVIg was proposed in $1990^{\circ}$ in the treatment of polyneuropathies associated with IgM monoclonal gammopathy. We conducted an open study in 13 cases of deteriorating IgM-associated polyneuropathy, with IVIg (Bio Transfusion) $2 \mathrm{~g} / \mathrm{kg}$ repeated in intervals of four weeks, for six months to two years. In three cases IVIg was stopped because of recurrent allergic rashes. Seven cases had previously been treated by immunosuppressive drugs without any beneficial effect; the characteristics of these patients are summarised in table 2 . We observed in $4 / 7$ cases an improvement of at least 1 grade at Prineas score (see table 2). The electrophysiological features, the IgM serum level and the antibody activity remained unchanged. The three last cases had no previous treatment and were treated with IVIg for five to 12 months: a significant improvement of the Prineas score was observed in two cases. Further controlled studies are necessary to discover whether IVIg can be considered as a treatment of poly-

Table 2 Polyneuropathies associated with IgM-MG: seven cases previously treated before IVIg

\begin{tabular}{|c|c|c|c|c|c|c|c|c|}
\hline \multirow[b]{2}{*}{$\begin{array}{l}\text { Number } \\
\text { of cases }\end{array}$} & \multirow[b]{2}{*}{ Sex/age } & \multirow[b]{2}{*}{$\begin{array}{l}\text { Course } \\
\text { (years) }\end{array}$} & \multirow[b]{2}{*}{$\begin{array}{l}\text { Treatments } \\
\text { before IVIg }\end{array}$} & \multirow[b]{2}{*}{$\begin{array}{l}\text { IgM antibody } \\
\text { activity }\end{array}$} & \multirow[b]{2}{*}{$\begin{array}{l}\text { IgM serum } \\
\text { level }(g / l)\end{array}$} & \multirow[b]{2}{*}{$\begin{array}{l}\text { Number of } \\
\text { IVIg infusions }\end{array}$} & \multicolumn{2}{|c|}{ Neurological score (Prineas) } \\
\hline & & & & & & & $\begin{array}{l}\text { Before } \\
\text { treatment }\end{array}$ & $\begin{array}{l}\text { After } \\
\text { treatment }\end{array}$ \\
\hline 1 & M/56 & 7 & $\mathbf{S}+\mathbf{P E}+\mathbf{I}$ & $\begin{array}{l}\text { Anti-GDla } \\
\text { Anti-GDlb }\end{array}$ & $4 \cdot 7$ & 3 & 3 & 2 \\
\hline 2 & M/45 & 5 & I & $\begin{array}{l}\text { Anti-MAG } \\
\text { Anti-SGPG }\end{array}$ & $4 \cdot 5$ & 11 & 4 & 3 \\
\hline 3 & $M / 68$ & 10 & $\mathrm{PE}+\mathrm{I}$ & $\begin{array}{l}\text { Anti-MAG } \\
\text { Anti-SGPG }\end{array}$ & 2 & 10 & 3 & 2 \\
\hline $\begin{array}{l}4 \\
5\end{array}$ & $\begin{array}{l}M / 47 \\
M / 62\end{array}$ & $\begin{array}{l}5 \\
7\end{array}$ & $\begin{array}{l}\mathrm{PE}+\mathrm{I} \\
\mathrm{PE}+\mathrm{I}\end{array}$ & $\begin{array}{l}\text { Anti-SGPG } \\
\text { Anti-MAG } \\
\text { Anti-SGPG }\end{array}$ & $\begin{array}{l}5 \cdot 5 \\
3\end{array}$ & $\begin{array}{r}9 \\
16\end{array}$ & $\begin{array}{l}3 \\
1\end{array}$ & $\begin{array}{l}3 \\
3\end{array}$ \\
\hline 6 & $F / 81$ & 6 & $\mathrm{PE}+\mathrm{I}$ & $\begin{array}{l}\text { Anti-MAG } \\
\text { Anti-SGPG }\end{array}$ & $4 \cdot 7$ & 6 & 2 & 4 \\
\hline 7 & $F / 53$ & 10 & $S+I$ & Anti-sulphatides & 5 & 7 & 4 & 3 \\
\hline
\end{tabular}

All patients noticed improvement of dysaesthesiae: $4 / 7$ improved 1 grade on $\mathrm{N}$ score; $1 / 7$ stable; $2 / 7$ deteriorated.

Neurological score (modified from Prineas by Nobile-Orazio ${ }^{29}: 0$ : normal; 1: signs but not symptoms of neuropathy or vice versa; 2: mild motor and/or sensory symptoms without or with mild functional impairment; 3: moderately disabled by motor or sensory symptoms including ataxia; 4: requiring assistance with eating, dressing, or using a walking aid; 5: not ambulant. $\mathrm{S}=$ steroids; PE = Plasma exchange; $\mathrm{I}=$ immunosuppressors. 
neuropathies associated with IgM monoclonal gammopathy.

\section{Polyneuropathy associated with IgG monoclonal gammopathy}

Polyneuropathies associated with IgG monoclonal gammopathy may be seen in multiple myeloma ${ }^{32}$ or solitary plasmocytoma, sometimes associated with a POEMS syndrome. ${ }^{33}$ Polyneuropathies associated with IgG-MGUS are heterogenous. They may present as sensorimotor distal polyneuropathies with electrophysiological and pathological features consistent with an axonopathy, a myelinopathy or a "mixed" peripheral neuropathy. No specific antibody activity has been demonstrated in these polyneuropathies.

Several treatments have been proposed, mainly with steroids, ${ }^{34}$ or plasma exchange. ${ }^{35}$ Recently, Dyck et al $^{36}$ conducted a double blind randomised trial with $\mathrm{PE}$ versus sham exchanges, and observed a significant improvement in polyneuropathies associated with IgG monoclonal gammopathy. We treated four patients with IgG-MGUS associated polyneuropathy, with IVIg given monthly at $2 \mathrm{~g} / \mathrm{kg}$, from three months to three years. We observed no response in two cases with axonal polyneuropathy, but a significant clinical improvement in two cases who had a chronic demyelinating polyneuropathy: one of these cases initially had a good response but returned to baseline despite periodic four day then two day IVIg infusions over a period of three years.

1 Van Der Meche FGA, Schmitz PIM and the Dutch Guillain-Barré study group. A randomized trial comparing intravenous immune globulin and plasma exchange in Guillain-Barré syndrome. $N$ Engl $\mathcal{F}$ Med 1992;326: $1123-9$.

2 Van Doorn PA, Brand A, Strengers PFW, Meulstee J, Vermeulen $M$. High-dose intravenous immunoglobulin treatment in chronic inflammatory demyelinating polyneuropathy: a double-blind, placebo-controlled, crossover study. Neurology 1990;40:209-12.

3 Van Doorn PA, Vermeulen M, Brand A, Mulder PGH, Bisch FM. Intravenous immunoglobulin treatment in patients with chronic inflammatory demyelinating polyneuropathy. Arch Neurol 1991;48:217-20.

4 Vermeulen M, Van Doorn PA, Brand A, Strengers PFW, Jennekens FGI, Busch HFM. Intravenous immunoglobulin treatment in patients with chronic inflammatory ulin treatment in patients with chronic inflammatory demyelinating polyneuropathy; a double-blind, placebo
controlled study. $₹$ Neurol Neurosurg Psychiatry 1993;56: contro

5 Chaudhry V, Corse AM, Cornblath DR, Kuncl RW, Drachman DB, Freimer ML, Miller RG, Griffin JW. Multifocal motor neuropathy: response to human immune globulin. Ann Neurol 1993;33:2437-42.

6 Cook D, Dalakas M, Galdi A, Biondi D, Porter H. Highdose intravenous immunoglobulin in the treatment of demyelinating neuropathy associated with monoclonal gammopathy. Neurology 1990;40:212-4.

7 Parry GJ, Clarke S. Multifocal acquired demyelinating neuropathy masquerading as motor neuron disease. neuropathy masquerading as

8 Roth G, Rohr J, Magistris MR, Oschner F. Motor neuropathy with proximal multifocal persistent block, fasciculations and myokymia. Evolution to tetraplegia. Eur Neurol 1986;25:416-23.

9 Lewis RA, Sumner AJ, Brown MJ, Asbury AK. Multifocal demyelinating neuropathy with persistent conduction block. Neurology 1982;32:958-64.

10 Pestronk A, Cornblath DR, Ilyas AA, Baba H, Quarles RH, Griffin JW, Alderson K, Adams RN. A treatable multifocal motor neuropathy with antibodies to GM1 ganglioside. Ann Neurol 1988;24:73-8.

11 Moulonguet A, Bouche P, Adams D, Ropert A, Leger JM, Said G, Meininger V. Patterns of conduction block motor neuropathy: a review of 18 patients. Neurology 1991;41(suppl 1):260

12 Lange D, Blake DM, Hirano M, Burns SM, Latov N, Trojaborg $W$. Multifocal conduction block motor neuropathy: diagnostic value of stimulating cervical roots. Neurology 1990;40(suppl 1):182

13 Auer RN, Bell RB, Lee MA. Neuropathy with onion bulb formations and pure motor manifestations. Can 7 Neurol Sci 1989;16:194-7.

14 Krarup C, Stewart MB, Sumner AJ, Pestronk A, Lipton SA. A syndrome of asymmetric limb weakness with motor conduction block. Neurology 1990;40:118-27.

15 Feldman EL, Bromberg MB, Albers JW, Pestronk A Immunosuppressive treatment in multifocal motor neuropathy. Ann Neurol 1991;30:397-401.

16 Cornblath DR, Chaudhry V, Griffin JM. Treatment of chronic inflammatory demyelinating polyneuropathy with intravenous immunoglobulin. Ann Neurol 1992;30: 104-6.

17 Nobile-Orazio E, Meucci N, Barbieri S, Carpo M, Scarlato G. High-dose intravenous immunoglobulin therapy in multifocal motor neuropathy. Neurology therapy in multion

18 Azulay JP, Blin O, Pouget J, Boucraut J, Bille-Turc F, Carles G, Serratrice G. Intravenous immunoglobulin treatment in patients with motor neuron syndromes associated with anti-GM1 antibodies: a double-blind placebo-controlled study. Neurology 1994;44:429-32.

19 Hoang-Xuan K, Leger JM, Ben Younes-Chennoufi A Saidi H, Bouche P, Baumann N, Brunet P. Traitement des neuropathies périphériques dysimmunitaires par immunoglobulines polyvalentes intraveineuses. $R e v$ Neurol 1993:149:385-93.

20 Ben Younes-Chennoufi A, Meininger V, Leger JM, Bouche P, Jauberteau MO, Baumann N. Antiganglioside antibodies in motor neuron diseases and peripheral neuropathies: study by Elisa technique and immunodetection on thin-layer chromatography. Neurochem Int 1992;20:353-7.

21 Garcin R, Mallarme J, Rondot P. Forme névritique de la macroglobulinémie de Waldenström. Bull Soc Med Paris macroglobuli

22 Smith IS, Kahn SN, Lacey BW, King RH, Eames RA, Whybrew DJ, Thomas PK. Chronic demyelinating neuropathy associated with IgM paraproteinemia. Brain 1983;106:169-95.

23 Leger JM, Vaunaize J. Polyneuropathy associated with gM monoclonal gammopathy: a review. Nouv Rev Fr Hematol 1990;32:303-6.

24 Braun P, Frail De, Latov N. Myelin associated glycoprotein is the antigen for a monoclonal IgM in polyneuropathy. $\mathcal{f}$ Neurochem 1982;39:1261-5.

25 Jauberteau MO, Henin D, Bouche $P$, et al. Etude des anticorps anti-glycolipides au cours des dysglobulinémies monoclonales à IgM associées à une neuropathie monoclonales à IgM associées à une

26 Ben Younes-Chennoufi A, Leger JM, Hauw J, et al. Ganglioside GDlb is the target antigen for a biclonal IgM in a case of sensory-motor axonal polyneuropathy; involvement of $\mathrm{N}$-acetylneuraminic acid in the epitope. Ann Neurol 1992;32:18-23.

27 Chassande B, Leger JM, Ben Younes-Chennoufi A Danon F, Baumann N, Bouche P, Brunet P. Polyneuropathy associated with IgM monoclonal gammopathy: correlations between M-protein antibody activity and clinical/electrophysiological features in 40 patients. Neurology 1994;44(Suppl 2):A379.

28 Dalakas MC, Flaum MA, Rick M, Engel W/, Gralnick HR. Treatment of polyneuropathy in Waldenström macroglobulinemia and immunologic studies. Neurology 1983;33:1406-10.

29 Nobile-Orazio E, Baldini L, Barbieri S, et al. Treatment of patients with neuropathy and anti-MAG IgM protein. patients with neuropathy
Ann Neurol 1988;24:93-7.

30 Mussini JM, Planchon B, Barrier J, Guimbretiere J. Plasma exchange in polyneuropathies accompanying IgM monoclonal gammopathy. Plasma Ther Transfus Technol 1985;6:443-7.

31 Leger JM, Oksenhendler E, Bussel A, Chastang A, Ben Younes-Chennoufi A, Danon F, Bouche P, Brouet JC and the French cooperative study group. Treatment by chlorambucil with/without plasma exchanges of polyneuropathy associated with monoclonal IgM: a prospective randomized control study in 44 patients. Neurology 1993;43(suppl 4):215-6.

32 Kelly J, Kyle RA, Miles JM, Dyck PJ. Osteosclerotic myeloma and peripheral neuropathy. Neurology 1983;33: 202-10

33 Fukase $M$, Tsunematsu $T$, Nisuitani $H$, Imura $H$, Matsukoha H. Report of a case of solitary plasmocytoma in the abdomen presenting polyneuropathy and endocrinal disorders. Clin Neurology 1969;9:657.

34 Meier C. Polyneuropathy in paraproteinemia. $f$ Neurol 1985;232:204-14

35 Fineman SM, McKendall RR. Plasma exchange: a treatment for neuropathy associated with IgG-kappa gammopathy. $\mathcal{f}$ Neurol 1990;237:85-7.

36 Dyck PJ, Low PA, Windenbank AJ, et al. Plasma exchange in polyneuropathy associated with monoclonal gammopathy of undetermined significance. $N$ Engl $f \mathrm{Med}$ 1991;21:1482-6. 